\title{
Análise dos aspectos institucionais da regulação de OGMs no Brasil: boas práticas de governança ambiental?
}

\section{Institutional Analysis of the Regulation of GMOs in Brazil: Good Environmental Governance Practices?}

\author{
Denise Gallo PIZELLA* \\ Marcelo Pereira de SOUZA**
}

\begin{abstract}
RESUMO
A liberação para o plantio de Organismos Geneticamente Modificados (OGMs) é um assunto controverso e que requer cuidados, pois envolve a segurança alimentar do país, a soberania dos produtores quanto às sementes utilizadas e os potenciais riscos ambientais em longo prazo. Deste modo, é importante uma análise da forma como as estruturas decisórias, tanto formais quanto informais, são estabelecidas para tratar destas questões, ou seja, a governança ambiental dos OGMs no Brasil, o que será o objetivo deste artigo. Dentre as boas práticas de governança a serem analisadas, utilizar-se-ão os seguintes parâmetros: participação popular nas tomadas de decisão, acesso às informações e à justiça ambiental. Como resultados obtiveram-se: do ponto de vista da participação pública, há falhas, já que os órgãos decisórios possuem pequena permeabilidade social, pois a CTNBio realiza audiências públicas apenas quando de sua decisão ou por mandado judicial, o que limita o acesso à participação na deliberação sobre os OGMs. Quanto ao acesso às informações, também se apontaram problemas, já que o Sistema de Informações em Biossegurança não se encontra implementado. A justiça ambiental é ineficiente, pois diversos casos de contaminação de variedades orgânicas e convencionais por OGMs prejudicam economicamente tais agricultores, especialmente os primeiros, que correm risco de perder as certificações de orgânicos. Além disto, a decisão sobre a realização de estudos de impacto ambiental é determinada pela CTNBio, ferindo princípios que atribuem tal tarefa aos órgãos do SISNAMA. Conclui-se, deste modo, que a regulação de OGMs no Brasil não apresenta boas práticas de governança ambiental.
\end{abstract}

Palavras-chave: governança ambiental; regulação de OGMs no Brasil; participação social; justiça ambiental; acesso às informações ambientais.

\footnotetext{
" Doutora em Ciências da Engenharia Ambiental (EESC-USP). Centro de Recursos Hídricos e Ecologia Aplicada (Escola de Engenharia de São Carlos - USP). E-mail: denisepizella@gmail.com

** Doutor em Saúde Ambiental (Faculdade de Saúde Pública - USP). Professor Titular do Departamento de Educação, Informação e Comunicação (Faculdade de Filosofia, Ciências e Letras de Ribeirão Preto - USP). E-mail: mps@usp.br
} 


\begin{abstract}
The release for the planting of Genetically Modified Organisms (GMOs) is a controversial issue and requires care because it involves the country's food security, the sovereignty of producers about seed use and the long-term potential environmental risks. Thus, it is important to analyze how the decision-making structures, both formal and informal, are established to address these issues, i.e. environmental governance of GMOs in Brazil, which is the purpose of this article. Among the good governance practices to be analyzed, we will be using the following parameters: popular participation in decision-making, and access to information and environmental justice. The following results were obtained: from the standpoint of public participation, there are flaws, as decision-makers have little social permeability, therefore CTNBio holds public hearings only by its own decision or by court order, which limits access to participation in the deliberation on GMOs. Regarding access to information, we also pointed out problems, as the Biosafety Information System has not been implemented. Environmental justice is inefficient since many cases of contamination of organic and conventional varieties by GMOs economically harm farmers, especially the first ones, who are at risk of losing their organic certification. Moreover, the decision on conducting environmental impact studies is determined by CTNBio, injuring principles that give this task to the organs of SISNAMA. We conclude therefore that the regulation of GMOs in Brazil does not have good environmental governance.
\end{abstract}

Keywords: environmental governance; GMO regulation in Brazil; social participation; environmental justice; openness to environmental information.

\section{Introdução}

A gestão dos Organismos Geneticamente Modificados (OGMs) é propícia ao exame das práticas de governança ambiental, por se tratar de atividades que lidam com bens de interesse coletivo da sociedade, como meio ambiente, saúde, bem-estar socio-econômico e valores culturais e éticos. Além disto, sobrepesam as incertezas existentes sobre os impactos ambientais e à saúde humana e dos demais animais que possam resultar de práticas biotecnológicas, em virtude de seu uso recente, evidenciando o conteúdo eminentemente político das decisões tomadas (LEVIDOW, 2007).

Em âmbito internacional, discussões estão sendo travadas no meio acadêmico, nas instâncias político-administrativas e na sociedade como um todo a respeito dos modelos regulatórios de gestão da biotecnologia, nos aspectos de legitimidade dos processos de decisão e critérios de avaliação a ser utilizados. Problemas relacionados à distribuição dos riscos e benefícios da tecnologia são postos em pauta, em um contexto em que empresas transnacionais dominam o mercado de produção de plantas geneticamente modificadas e os riscos ambientais, sociais e econômicos são alocados aos indivíduos que consomem produtos contendo OGMs, aos produtores de cultivos orgânicos e ao meio ambiente de modo geral (COCKLIN; DIBDEN; GIBBS, 2008).
O desafio da governança e regulação dos transgênicos por parte dos estados nacionais constitui-se, portanto, na criação de mecanismos socialmente acordados que possibilitem avaliar e sobrepesar os riscos e benefícios advindos da utilização de OGMs a todos os setores afetados, norteando-se pelos princípios de justiça ambiental, legitimidade, participação social nas tomadas de decisão, acesso às informações, prestação de contas, dentre outros localmente considerados importantes.

O Protocolo de Cartagena sobre Biossegurança, documento norteador na gestão de OGMs aos países signatários (dos quais o Brasil faz parte) apresenta como princípio geral a vigência do princípio da precaução nos processos decisórios sobre OGMs, dadas as incertezas científicas sobre os possíveis impactos ambientais, econômicos e sociais advindos de sua utilização (BRASIL, 2006). Não obstante as características próprias de cada nação, tal princípio se faz presente em praticamente todos os modelos regulatórios de OGMs ao redor do mundo. No processo de análise de risco, o critério de avaliação utilizado se baseia, geralmente, na comparação estrutural da variedade transgênica com sua contraparte convencional, denominado Princípio da Equivalência Substancial. Alguns países (Áustria e Itália), entretanto, utilizam variedades orgânicas como parâmetro, visando ao incentivo aos sistemas orgânicos de cultivo, considerados social e ambientalmente mais adequados (LEVIDOW; BOSCHERT, 2008). 
De qualquer modo, a gestão de OGMs não pode ser considerada apenas em seu aspecto técnico, pois o processo de análise de risco envolve a identificação dos perigos, sua comunicação e gerenciamento, os quais dependem dos valores sociais e indicam quais e como os recursos naturais devem ser protegidos. Os riscos incertos impostos pela biotecnologia e os juízos de valor presentes em todas as etapas de avaliação da tecnologia quanto à definição do escopo de análise, formulação das hipóteses, termos de referência e critérios de análise, interpretação, ponderação dos resultados e tomada de decisão requerem a abertura de canais entre governo, academia e sociedade, visando à legitimidade e à transparência dos processos decisórios, à confiança pública nas instâncias de decisão, à prestação de contas e à aplicação prática dos princípios democráticos (LEVIDOW; BOSCHERT, 2008).

No Brasil, alguns atores apontam para o prevalecimento de interesses econômicos nas políticas de biotecnologia, em nome do progresso científico e da competitividade internacional, em detrimento da segurança ambiental, da saúde e do bem-estar social (PELAEZ, 2004). De fato, documentos estratégicos do Ministério da Agricultura, Pecuária e Abastecimento apresentam o claro posicionamento do governo como favorável aos ditames da bioindústria, caracterizando os clamores de cautela na liberação ambiental de OGMs como ideológicos e contrários ao desenvolvimento do país (MINISTÉRIO DAAGRICULTURA, PECUÁRIA E ABASTECIMENTO, 2006, p. 9):

Nossos concorrentes investem somas astronômicas em tecnologias de ponta, como a biotecnologia, incluindo os produtos transgênicos e a nanotecnologia. Precisamos nos manter atualizados na área, sob pena de sermos atropelados pela concorrência. É preciso sempre ter em mente que em matéria de pesquisa científica não cabem posturas preconceituosas ou ideologizadas.

O incentivo ao desenvolvimento da agrobiotecnologia por meio de mecanismos regulatórios favoráveis à bioindústria não é fato isolado do Brasil e se faz presente em diversas nações, cabendo maior destaque aos Estados Unidos da América, em razão de sua influência política internacional. Levidow (2007) denomina tal imperativo de "determinismo tecnológico". Neste sentido, as análises de risco como ferramentas únicas para o apoio às tomadas de decisão, sob o pretexto do racionalismo científico supostamente imparcial, são utilizadas para justificar o impedimento da instauração de processos participativos.

No Brasil, a análise da governança ambiental envolvendo a liberação comercial de OGMs é realizada neste artigo pelo fato de tratar de interesses difusos e conflituosos, relacionados de forma interdependente ao meio ambiente, à saúde humana e ao bem-estar social. Deste modo, entende-se que a consideração desta questão seguindo as premissas de uma boa governança ambiental contribuiria para uma maior legitimidade de seus mecanismos decisórios. Segundo O'Connor e van den Hove (2001, p. 80) “quando os riscos são elevados, valores divergem e as escalas temporais são longas, abordagens puramente técnicas para a avaliação de riscos e governança não são robustas”. Neste sentido, um processo participativo que envolva todos os interessados na ação durante as fases de julgamento, gestão e decisão possibilitam resultados mais adequados.

\section{Metodologia}

Serão analisados os seguintes aspectos institucionais relacionados à regulamentação de OGMs no país, que tratam da governança ambiental desta questão:

1. Legitimidade, transparência e participação social nas tomadas de decisão;

2. Acesso às informações ambientais;

3. Justiça ambiental.

\section{Resultados e discussão}

\section{Legitimidade, transparência e participação social nas tomadas de decisão}

O Conselho Nacional de Biossegurança, criado em 2003, tinha por atribuição reformular a legislação de biossegurança, visando ao término dos conflitos judiciais relacionados às sucessivas medidas provisórias de liberação da soja transgênica. Tal processo foi realizado em três etapas: a criação do projeto de lei, coordenado pela Casa Civil, sua aprovação pelo Congresso Nacional e a regulamentação da lei. O projeto de lei, que se estendeu no Congresso por dois anos em razão de disputas político-partidárias, passou por diversas modificações, sendo o projeto inicial mais restritivo em relação à Lei 8.975/95, principalmente quanto ao 
caráter consultivo e não deliberativo da CTNBio em relação a pesquisas e à comercialização de OGMs. Tal projeto de lei, que atendia às reivindicações dos Ministérios da Saúde e do Meio Ambiente, de associações de consumidores e ambientalistas, procurava manter a atribuição dos órgãos de registro e fiscalização de OGMs (Ministérios da Saúde, Agropecuária e Abastecimento e Meio Ambiente) para autorizar pesquisas e a comercialização destes organismos no Brasil. No entanto, não atendia aos interesses das empresas multinacionais produtoras de sementes e setores ligados à biotecnologia (PELAEZ, 2007). Entretanto, no Congresso Nacional e, principalmente no Senado, o projeto de lei sofreu alterações e o texto final foi aprovado em 2005, originando a Lei $\mathrm{n}^{\circ}$ 11.105/05, sendo as mais significativas relacionadas às atribuições dos órgãos responsáveis pela regulação da Biossegurança no Brasil. Neste sentido, estabeleceu-se a CTNBio como órgão deliberativo sobre as pesquisas e liberações comerciais de OGMs, com a prerrogativa de decidir sobre a realização de estudos de impactos ambientais, enquanto que os Ministérios da Saúde, Meio Ambiente e Agropecuária e Abastecimento passaram a ser órgãos responsáveis pelo registro e pela fiscalização, segundo as normas da CTNBio (PELAEZ, 2007).

De acordo com o Ministério Publico Federal (BRASIL, 2007), as competências da CTNBio determinadas na Lei de Biossegurança ferem os princípios previstos na Constituição Federal e na Lei n. ${ }^{\circ}$ 6.938/81 (Política Nacional de Meio Ambiente) que dispõem sobre o papel do IBAMA na gestão do meio ambiente, pois:

- ao IBAMA cabe a formulação, coordenação e execução da Política Nacional de Meio Ambiente, assim como a fiscalização e controle das atividades que envolvem o uso de recursos naturais. Deste modo, as competências da CTNBio (órgão que não faz parte do SISNAMA) fixadas na Lei de Biossegurança confrontam tais determinações;

- os estudos de impacto ambiental, um dos instrumentos utilizados para a efetivação do princípio da precaução, devem ser solicitados e analisados por diversos órgãos da administração pública, dentre os quais o IBAMA e a ANVISA. A desconsideração deste princípio em casos de potenciais danos ambientais seria qualificada como crime, segundo o MPF, como estabelecido na Lei de Crimes Ambientais n. ${ }^{\circ} .9 .605 / 98$, ou seja, “[...] incorre nas mesmas penas previstas no parágrafo anterior quem deixar de adotar, quando assim o exigir a autoridade competente, medidas de precaução em caso de risco de dano ambiental grave ou irreversível" (BRASIL, 1998, art. 54, § 3..$^{\circ}$ );

- dentre as atividades potencialmente poluidoras que requerem licenciamento ambiental (e que, portanto, necessitam de apresentação de estudos de impactos ambientais prévios) encontra-se a introdução de espécies exóticas e/ou geneticamente modificadas (CONAMA, 1986).

A Lei de Biossegurança, quando submetida à sanção presidencial, apresentou vetos em sete artigos, dentre os quais se cabe citar: "As decisões da CTNBio serão tomadas por maioria dos membros presentes à reunião, respeitado o quórum [mínimo de 14 membros] previsto no $\S 7^{\circ}$. deste artigo" (BRASIL, 2005, artigo 11, $\S 8 .^{\circ}$ ), sendo a justificativa para tanto o fato da complexidade da questão, que, tendo o potencial de afetar a saúde e o meio ambiente, não poderia ser decidida por oito cidadãos, mesmo que academicamente qualificados, já que o quórum para a realização das reuniões é de 14 membros e sua maioria, portanto, composta por oito membros (BRASIL, 2005). Tal alteração foi motivo de diversas discussões entre representantes de setores variados da sociedade, partidos políticos e órgãos ministeriais competentes, sendo solucionada com a sanção presidencial favorável à tomada de decisões na CTNBio por $2 / 3$ de seus membros. Uma das manifestações contrárias a tal decisão foi realizada pelo presidente da Federação dos Agricultores do Rio Grande do Sul, a FARSUL, com a seguinte argumentação: “[...] Lastimo que todas as ações do [Ministério do] Meio Ambiente sejam para dificultar e atrasar os procedimentos. Como se isso viesse a segurar o avanço da biotecnologia" (FARSUL apud PELAEZ, 2007, p. 12).

Neste mesmo sentido, o presidente da Comissão de Agricultura da Câmara dos Deputados, Ronaldo Caiado, que também discordou do veto, afirmou a possibilidade de reverter tal decisão, na medida em que a "bancada que representa os grandes produtores rurais no Congresso é numerosa e muito articulada" (ZANATTA, 2005 apud PELAEZ, 2007). Com a regulamentação da nova Lei de Biossegurança, sua composição foi alterada de 18 para 27 membros, dobrando-se os representantes da sociedade civil, que passaram de 3 para 6 . A partir deste momento, uma série de irregularidades foram cometidas em relação à nomeação dos membros da CTNBio, notadamente quanto ao representante do Ministério da Saúde. De acordo com a nova lei, cabe ao Ministro da Saúde escolher seu represen- 
tante na Comissão, a partir de uma lista tríplice indicada por seus pares. No entanto, sem atender ao disposto em lei, o Ministro indicou diretamente seu representante, sem avaliar qualquer lista tríplice. O membro da Comissão escolhido pelo Ministro, Dr. Walter Colli, terminou por ser nomeado o Presidente da CTNBio, posteriormente. Em razão da irregularidade, algumas ONGs ambientalistas entraram com recurso no Ministério Público Federal, por meio de uma ação civil pública, contra a referida nomeação. Entretanto, a liminar foi negada e o MPF recorreu da decisão (ZANATTA, 2007 apud PELAEZ, 2007).

Deste modo, o Ministério Público, em vista das suspeitas levantadas, decidiu por nomear a procuradora Maria Soares Cordioli para assistir às reuniões da Comissão, gerando constrangimentos entre alguns de seus membros e a aprovação dos Ministérios do Meio Ambiente e Desenvolvimento Agrário, que viram nesta decisão a possibilidade de contribuir para uma maior transparência nas decisões da Comissão. A ação da procuradora inicialmente foi pedir aos membros da Comissão uma declaração de conflitos de interesse, prevista na Lei de Biossegurança, mas que até então não havia sido realizada (PELAEZ, 2007). Quanto ao quórum para a liberação comercial de OGMs, em razão de diversas manifestações contrárias provenientes de produtores rurais, biotecnólogos, empresas de biotecnologia, dentre outros, que viam neste número uma inviabilização das liberações, conduziram o governo à edição de uma Medida Provisória (MP 327) visando à sua diminuição para a maioria absoluta dos membros da Comissão, além de permitir também o plantio de OGMs no entorno das Unidades de Conservação (PELAEZ, 2007).

De acordo com a nova Lei de Biossegurança, apenas para seis membros titulares da CTNBio podem ser apresentadas listas tríplices elaboradas pela sociedade civil para a nomeação por parte dos respectivos ministérios. Constata-se, desta forma, a pequena influência da sociedade civil na correlação de forças na composição do órgão superior de decisão sobre a liberação de OGMs no Brasil. Além disto, sobrepesa o critério de escolha baseado na titulação acadêmica, impossibilitando considerações sobre outras formas de saber e atuação dos candidatos. Na prática, um fato a ser observado na composição da CTNBio é presença majoritária de especialistas atuantes nas áreas de bioquímica, biologia molecular, genética molecular e biotecnologia, inclusive dentre os especialistas da área ambiental. A interdisciplinaridade requisitada para o tratamento adequado de um tema multifacetado, como o caso dos OGMs, em razão de suas implicações sociais, ambientais e econômicas, não se faz ecoar na estrutura do órgão soberano de decisão, acarretando problemas de falta de legitimidade e confiança pública e ameaçando a integridade dos bens sociais coletivos. Já em relação ao Conselho de Biossegurança, outro órgão importante no sistema regulatório brasileiro, a participação de entidades da sociedade civil pode ser concedida apenas em caráter excepcional, quando este assim o determinar (BRASIL, 2005).

Um momento importante para a participação dos setores interessados no processo decisório sobre OGMs seria dado com a realização de audiências públicas, indispensáveis para a consulta popular sobre o objeto em avaliação, apesar do caráter passivo do método no tocante à influência exercida pela sociedade sobre a decisão final. Em razão de as atividades relacionadas à pesquisa, ao plantio e à comercialização de OGMs não se encontrarem sujeitas ao processo de licenciamento ambiental, a menos que a CTNBio solicite a realização de Estudos de Impacto Ambiental, os quais vinculam o processo decisório à realização de audiências públicas, a Lei de Biossegurança confere à CTNBio a faculdade de decidir, perante solicitação de $1 / 3$ de seus membros, sobre a efetuação ou não destas audiências. A Instrução Normativa n. ${ }^{\circ} 19$, de 19 de abril de 2000 (CTNBIO, 2000), que dispõe sobre os procedimentos para a realização de audiências públicas pela CTNBio, as apresenta com o objetivo instrutivo de esclarecimento à sociedade sobre os aspectos técnico-científicos relacionados à biossegurança, além de possibilitarem o debate meramente técnico-científico sobre a biossegurança de OGMs. Entretanto, a participação social é na verdade limitada, na medida em que a própria Comissão, na autoridade de seu presidente, seleciona as pessoas que solicitam realizar apresentações durante as audiências públicas (CTNBIO, 2000).

Além disto, cabe à Comissão considerar ou não os aspectos abordados pela sociedade civil durante as audiências e, em algumas situações, o número de seus participantes é limitado, pois os locais destinados à realização das audiências não são fixos e elas são realizadas nos anfiteatros que se encontram disponíveis no momento. Na audiência pública sobre algumas variedades de algodão, por exemplo, havia apenas 500 assentos para 943 inscritos. Nesta situação, perante as reivindicações de participação por parte de membros da sociedade, as palavras do presidente da CTNBio, Walter Colli, foram as seguintes (CTNBIO, 2007, p. 3): 
[...] foram 943 inscritos e nós já havíamos acertado este anfiteatro que, ainda bem é grande, mas só cabem 490, 500 pessoas, então algumas pessoas ficarão de fora, infelizmente, mas não se pode fazer nada. Eu não pensei em contratar o Estádio Mané Garrincha para fazer a audiência de algodão, infelizmente.

Uma das funções da CTNBio é considerar os pareceres dos relatores de Comissões Setoriais, em se tratando da análise de processos sobre a comercialização de OGMs. No caso dos processos relativos ao algodão RR e milho Bt da Monsanto $^{1}$, diversas incertezas levantadas quanto às consequências ambientais e sobre o conteúdo das informações concedidas pela empresa foram desconsideradas nos pleitos, que favoreceram a liberação das referidas Plantas Geneticamente Modificadas (PGMs). A Comissão não solicitou esclarecimentos quanto aos questionamentos levantados por alguns relatores das áreas ambiental e de saúde, mesmo em relação aos casos confirmados de contaminação genética (como o milho MON810 no México) e anomalias encontradas em órgãos de animais submetidos à alimentação contendo o milho transgênico. Estas e outras argumentações também se sucederam nas audiências públicas, mas não foram objeto de atenção da Comissão. A desconsideração destes fatos e incertezas fere o princípio da precaução preconizado inclusive no Protocolo de Cartagena ${ }^{2}$ e denotam a ausência de transparência nas decisões tomadas pela CTNBio.

Em razão da ausência de permeabilidade social dos setores interessados nas tomadas de decisão envolvendo a liberação comercial de OGMs, da inconstitucionalidade de atribuição do poder de decisão final da CTNBio, inclusive em se tratando da solicitação de estudos de impactos ambientais, os quais não foram exigidos para quaisquer das variedades de PGMs até então liberadas, pode-se considerar o aspecto "legitimidade, transparência e participação social nas tomadas de decisão", que caracteriza uma boa prática de governança ambiental no sistema regulatório de OGMs no Brasil, como insatisfatório.

\section{Acesso às informações ambientais}

O direito dos cidadãos brasileiros à informação se faz presente na Constituição Federal de 1988, sob o artigo 5. ${ }^{\circ}$, no capítulo sobre os direitos e deveres individuais e coletivos do título II. Especificamente em relação ao meio ambiente, a Política Nacional de Meio Ambiente apresenta como um dos instrumentos para o cumprimento dos objetivos de sustentabilidade econômica, ambiental e social, o sistema nacional de informações sobre o meio ambiente, por meio do artigo $9 .^{\circ}$, inciso VII, o qual, no entanto, ainda não se encontra regulamentado pelo Conselho Nacional do Meio Ambiente. Buscando suprir tal vazio regulatório, em 2003, o Congresso Nacional aprova a Lei n. ${ }^{\circ}$ 10.650, denominada Lei de Acesso à Informação Ambiental, pela qual os órgãos públicos pertencentes ao SISNAMA ficam obrigados a permitir o livre acesso "[...] aos documentos, expedientes, e processos administrativos que tratem de matéria ambiental e a fornecer todas as informações ambientais que estejam sob sua guarda, em meio escrito, visual, sonoro ou eletrônico [...] (BRASIL, 2003a, art. 2), sendo que, dentre as principais atividades ressaltadas, encontram-se aquelas relacionadas aos organismos geneticamente modificados.

Um dos instrumentos dispostos legalmente para a garantia de informações ambientais sobre os OGMs no Brasil é a rotulagem dos produtos alimentícios destinados ao ser humano e demais animais, regulamentada pelo Decreto n. ${ }^{\circ} 4.680$ de 24 de abril de 2003, mas que não se encontra efetivada, devido às dificuldades encontradas pelos órgãos fiscalizadores e responsáveis para punição de seus infratores. Visando ao seu estabelecimento, o governo federal atribuiu o ano de 2004 como prazo final para as empresas se adequarem à norma e efetuarem a rotulagem de seus produtos, identificando os alimentos contendo mais de $1 \%$ de OGMs com a letra " $T$ ". No entanto, o mesmo não se sucedeu, sob as justificativas da falta de preparo dos laboratórios certificados pelo governo para o atendimento da demanda, dentre os quais se encontra a própria ANVISA. Deste modo, até o presente, a rotulagem não se encontra implementada, ferindo o direito fundamental dos brasileiros de acesso à informação.

\footnotetext{
${ }^{1}$ Indústria multinacional de agricultura e biotecnologia. Situada nos EUA, é hoje, em sua maior parte, francesa. É, de longe, o produtor líder de sementes geneticamente modificadas (transgênicos).

${ }^{2}$ O Protocolo de Cartagena sobre Biossegurança é um tratado sobre biossegurança assinado durante a Convenção sobre Diversidade Biológica (CDB) em Cartagena, Colômbia. Aprovado em 29 de janeiro de 2000 e em vigor desde setembro de 2003, o texto disciplina questões envolvendo o estudo, a manipulação e o transporte de organismos geneticamente modificados (OGM) entre os países membros do acordo.
} 
Como outro modo de se garantir o acesso às informações sobre OGMs, é prevista na Lei n. ${ }^{\circ} 11.105$, de 2005, a criação do Sistema Nacional de Informações em Biossegurança (SIB), com fins de "[...] gestão das informações decorrentes das atividades de análise, autorização, registro, monitoramento e acompanhamento das atividades que envolvam OGMs e seus derivados" (BRASIL, 2005, Cap. VI, artigo 19), para a qual os órgãos de registro e fiscalização também devem colaborar com o aporte de informações. Entretanto, o SIB ainda não se encontra implementado, sendo as informações relativas aos processos, avaliações, aprovações e legislações sobre biossegurança não sistematizadas. No meio eletrônico, informações dispersas são encontradas nos órgãos que compõem o sistema regulatório da biotecnologia, principalmente a CTNBio, o Ministério da Agricultura e a ANVISA. No portal da CTNBio estão presentes os documentos que se relacionam às suas funções, como: processos e pareceres técnicos sobre os pedidos de liberação comercial e importação de OGMs, atas e calendários de reuniões, documentos publicados no Diário Oficial da União, relatórios anuais, declarações de voto, legislação de biossegurança e as normativas elaboradas pela Comissão. No entanto, outros documentos fundamentais, como as informações prestadas pelos requerentes sobre as análises de risco e os critérios utilizados pelo órgão para a avaliação dos processos, não se encontram disponíveis. Além disto, não há elementos que possibilitem interações com os órgãos de registro e fiscalização e o CNBS, como previsto no SIB (MINARÉ, 2008).

O Ministério da Agricultura, Pecuária e Abastecimento, por sua vez, apresenta os registros dos cultivares liberados comercialmente, as instruções normativas e portarias do MAPA, os atos do CNBS e da CTNBio, a lista dos laboratórios credenciados para a detecção, identificação e quantificação de OGMs, mas não apresenta os relatórios sobre a fiscalização de atividades ilícitas envolvendo OGMs em território nacional. Já o portal da ANVISA apresenta a legislação pertinente e notícias dispersas, também sem sistematização, enquanto que os portais do Ministério do Meio Ambiente e do IBAMA não apresentam informações sobre o tema. Deste modo, o SIB se configuraria como uma ferramenta importante para a apresentação das informações de forma sistematizada e retroalimentada pelos diversos órgãos que compõem o sistema regulatório e, em conjunto com a rotulagem dos produtos alimentícios, o atendimento ao princípio de acesso às informações como boa prática de governança ambiental poderia se mostrar minimamente satisfatório.

\section{Acesso à justiça ambiental}

Um dos aspectos relevantes para avaliar a justiça ambiental em se tratando de OGMs de aplicação agrícola no Brasil é a garantia de escolha do agricultor em adotar o sistema de plantio que melhor lhe convir, seja este convencional, transgênico ou orgânico, sem afetar os direitos dos demais neste mesmo sentido, assim como o direito coletivo ao meio ambiente ecologicamente equilibrado, ao bem-estar e à saúde.

No Brasil, apenas o sistema de cultivo orgânico apresenta requisitos próprios de identificação e um sistema definido de controle, representado pelo Sistema de Avaliação da Conformidade Orgânica, apresentados pela Lei Federal n. ${ }^{\circ} 10.831$, de 23 de dezembro de 2003, denominada de Lei de Orgânicos. A fim de se assegurar a procedência orgânica do alimento, o produto deve passar por um sistema de certificação, sendo o produtor infrator sujeito a processo administrativo, sanções econômicas e, dependendo do caso, até mesmo à inutilização de sua produção (BRASIL, 2003b). A implementação de sistemas produtivos paralelos ao orgânico é permitida desde que se garanta a separação dos produtos nas etapas de plantio, processamento e armazenamento, por meio de seu isolamento espacial e temporal (BRASIL, 2003b, cap. II, seção II, art. 7, §§ 1. ${ }^{\circ}, 2 .^{\circ}$ e $3 .^{\circ}$ ). Além disto, a produção orgânica não pode conter qualquer traço de modificação genética, nem mesmo no limite de $1 \%$ exigido legalmente para a rotulagem (BRASIL, 2003b).

Pelas disposições da regulamentação deste sistema agrícola, a produção de alimentos orgânicos como um todo necessita de medidas de segregação entre os produtos desenvolvidos pelo método convencional ou pela transgenia, o que depende de uma rede fiscalizadora estruturada. No entanto, de acordo com diversas denúncias relatadas pelo Ministério Público Federal (BRASIL, 2007), agricultores orgânicos e organizações não governamentais, evidenciadas pela constatação da presença adventícia de OGMs em sistemas de plantios orgânicos e convencionais (acima de 1\%), há falhas no processo de fiscalização realizado pelo MAPA, MS e MMA, fato que vem sendo desconsiderado quando da autorização de plantios geneticamente modificados pela CTNBio (BRASIL, 2007). Assim como para o agricultor orgânico, que necessita de garantias legais para assegurar seu sistema de plantio, o consumidor também deve ter assegurado o acesso às informações sobre a procedência dos produtos alimentícios, como expresso no Código de Defesa do Consumidor. Em relação aos alimentos OGMs 
ou que os contenham, uma forma para permitir tal acesso é a identificação dos produtos contendo traços de transgenia acima de $1 \%$ por meio de rotulagem, o que, apesar de legalmente garantido, não vem sendo cumprido no país, dada a ausência de fiscalização e punição das empresas contraventoras, como anteriormente mencionado.

Outro aspecto dificultador da justiça ambiental em matéria de OGMs no Brasil é dado pela inexistência de monitoramento ambiental pós-comercial (apesar de sua exigência na Lei de Biossegurança), o que se configura em uma afronta aos direitos fundamentais dos cidadãos brasileiros ao meio ambiente sadio e à boa qualidade de vida, já que não possibilita a detecção de danos ambientais e à saúde, incorrendo em um ônus muitas vezes irreparável aos sistemas biológicos e populações humanas afetadas. Os princípios de gestão e comunicação dos riscos que necessariamente devem participar de uma análise de risco ambiental prévia às liberações, como exigido na legislação pertinente sobre OGMs no país, ficam, deste modo, totalmente inviabilizados. A fiscalização e o monitoramento são indispensáveis para a garantia da integridade dos cultivos e dos alimentos de origem convencional e orgânica, minimizando, deste modo, o escape gênico que pode ocorrer por cruzamento destas variedades com as transgênicas pela polinização, com a deposição de sementes GMs em áreas inadequadas durante seu transporte e com eventuais misturas de variedades no processo de armazenamento. A ausência destes mecanismos impede que medidas de prevenção e reparação de danos sejam executadas.

A caracterização de um sistema regulatório de recursos naturais como sendo ambientalmente justo passa também pela forma como os órgãos decisórios conduzem a mediação dos conflitos existentes, de modo a evitar que benefícios e danos sejam desigualmente distribuídos pelos grupos sociais afetados. Alguns casos emblemáticos que possibilitam uma análise geral desta questão no Brasil são apresentados. O caso da soja resistente ao glifosato, da Monsanto, é um dos mais comentados na literatura. Esta variedade é ilegalmente introduzida no país, em larga escala, durante a década de 1990, provavelmente por meio da Argentina. Não obstante tal contravenção, pressões políticas da bancada ruralista do Congresso Nacional e de organizações de agricultores da região Sul ligados ao agronegócio, clamando pela liberação das safras de 2002 e 2003 contendo soja transgênica, conduzem o governo a editar as Medidas Provisórias n. ${ }^{\circ} 113$, de 26 de março de 2003, e n. ${ }^{\circ} 131$, de 25 de setembro de 2003, esta última convertida em lei por meio do Decreto n. ${ }^{\circ} 10.814$, de 15 de dezembro de 2003. Tal Decreto apresenta a inteira responsabilização do agricultor aos danos ambientais e econômicos ocasionados pela presença adventícia de soja transgênica em sua lavoura, mesmo quando o transgênico não tenha sido por ele cultivado, assim como viabiliza a cobrança, por parte da Monsanto, dos royalties das sementes contaminadas pelo transgene.

Em 2004, outra Medida Provisória (n. ${ }^{\circ}$ 223, de 14 de outubro de 2004), visando autorizar a safra ilegal de 2004/2005, é editada, mantendo os mesmos dispositivos da MP anterior. Deste modo, independentemente de o agricultor ter ou não introduzido tais variedades propositalmente, fica sujeito ao pagamento de indenizações pelos possíveis danos ocasionados, assim como a transferir parte de seus rendimentos à detentora da propriedade intelectual da tecnologia. Neste sentido, tendo em vista o Princípio da Precaução e a inconstitucionalidade das referidas Medidas Provisórias, o Ministério Público Federal, por solicitação do Instituto de Defesa do Consumidor, entra com uma Ação Civil Pública contra União Federal e o Estado do Rio Grande do Sul, proibindo a aplicação do herbicida glifosato no cultivo da soja transgênica liberada, a qual é indeferida (BRASIL, 2007).

Outra evidência sobre a adoção da política "do fato consumado" em assuntos relativos aos OGMs é a autorização, pela CTNBio, da comercialização da safra de algodão 2004/2005, que contém presença adventícia de algodão Bt em $1 \%$, até então proibido no país. Neste momento, o Ministério do Meio Ambiente entra com recurso administrativo contra a autorização, alegando a ausência de avaliações de risco ambiental e à saúde pelo algodão transgênico exigidas de modo prévio às liberações e o descumprimento do quórum mínimo exigido nas tomadas de decisão da CTNBio (BRASIL, 2007). No entanto, a decisão judicial final termina por ser favorável à CTNBio e a safra é liberada.

Conflitos judiciais são também suscitados com a liberação das variedades de milho transgênico Liberty Link, desenvolvido pela Bayer, MON 810, da Monsanto e Bt11, da Syngenta. Em 15 de junho de 2006, organizações da sociedade civil, como Terra de Direitos, IDEC, ASP-TA e ANPA, solicitam ação civil pública contra a União, com o objetivo de anular a decisão favorável da CTNBio pela liberação comercial da variedade, alegando uma série de afrontas à legislação brasileira ao longo do processo decisório, quais sejam: ausência de normatização que oriente a CTNBio para a avaliação da biossegurança de OGMs; falta 
de regras de monitoramento e coexistência com o milho convencional e orgânico; desconsideração dos documentos apresentados por diversas organizações da sociedade civil no processo e insuficiência de informações prestadas pela proponente que assegurassem a biossegurança do produto. Em julho do mesmo ano, o IBAMA e a ANVISA apresentam recurso no CNBS contra também a decisão da CTNBio de liberar o milho LL. Deste modo, a Comissão é judicialmente obrigada a condicionar a liberação do milho transgênico a uma medida de coexistência, fixando a distância mínima de $100 \mathrm{~m}$ entre o milho GM e não modificado, por meio da Resolução Normativa n. ${ }^{\circ} 4$, de agosto de 2007. No entanto, em razão do apontamento, por diversos agrônomos, sobre a ineficácia da distância mínima estabelecida para evitar o cruzamento entre as variedades de milho, a Justiça entra novamente com ação contra a decisão da CTNBio, alegando sua desobediência ao Princípio da Precaução, não obtendo sucesso (THUSWOHL, 2007; PARANAONLINE, 2008).

Em razão das evidências apontadas de descumprimento, por parte da administração pública, de diversos dispositivos legais ao longo do histórico dos OGMs de aplicação comercial no Brasil, tais como:

- a medida judicial que proibia a liberação da soja transgênica RR da Monsanto até a entrada em vigor da nova Lei de Biossegurança, por meio de sucessivas Medidas Provisórias que visaram à legalização do plantio;

- as tomadas de decisão da CTNBio sem respaldo científico, já que não se realizam avaliações de risco independentes daquelas fornecidas pelas empresas interessadas;

- o descumprimento de medidas de manejo dos riscos aos proponentes, como o monitoramento ambiental pós-comercial o qual, apesar de exigido pela Lei de Biossegurança, inexiste para todas as PGMs liberadas comercialmente;

- a não adoção de medidas de coexistência com outros sistemas produtivos que visem evitar a contaminação das variedades convencionais e orgânicas pelos transgenes;

- a desresponsabilização dos produtores de transgênicos e das empresas detentoras das patentes sobre os danos ambientais, sociais e econômicos causados aos produtores de alimentos orgânicos ou convencionais;

- as deficiências dos órgãos de registro e fiscalização para o cumprimento de suas funções;
- a inexistência da rotulagem dos alimentos contendo transgênicos, apesar da existência da Lei de Rotulagem.

Por conta destes e de outros fatores, infere-se que a justiça ambiental no caso de PGMs comercializadas no Brasil é bastante deficiente.

\section{Conclusões}

No Brasil, a análise da governança ambiental envolvendo a liberação comercial de OGMs foi tomada como objeto do presente artigo pelo fato de tratar de interesses difusos e conflituosos, relacionados de forma interdependente ao meio ambiente, à saúde humana e ao bem-estar social. Deste modo, entende-se, de acordo com os princípios democráticos que regem o arcabouço legal do país, inclusive em se tratando da gestão ambiental, que a consideração desta questão seguindo as premissas de uma boa governança ambiental contribuiria para uma maior legitimidade de seus mecanismos decisórios. De acordo com as práticas de boa governança ambiental, procurou-se analisar o estado de governança ambiental do sistema regulatório de OGMs no Brasil, obtendo-se os seguintes resultados:

Participação social: os agentes que participam do processo decisório envolvendo a liberação comercial de OGMs no país são escolhidos de acordo com o mérito acadêmico, pelo Ministro da Ciência e Tecnologia e titulares dos Ministérios que compõem a CTNBio. As audiências públicas são convocadas apenas quando solicitadas ou autorizadas pela Comissão, a qual também define o conteúdo das mesmas e seus participantes. Deste modo, as regras do jogo acabam sendo totalmente definidas pelo poder formal, caracterizando a governança do sistema como não democrática, em uma estruturação "de cima para baixo".

Acesso às informações ambientais: apesar de a Lei n. ${ }^{\circ} 11.105 / 05$ dispor sobre a necessidade de se criar um Sistema Nacional de Informações sobre Biossegurança para a disponibilização pública e o disciplinamento das informações relativas ao assunto, o Conselho Nacional de Biossegurança, órgão responsável por sua elaboração, ainda não tomou medidas para sua efetivação. Deste modo, as informações, quando existentes, encontram-se dispersas entre os diversos órgãos atuantes do sistema regulatório, o que dificulta sua obtenção e análise por parte dos interessados. Do mesmo modo, a rotulagem dos produtos que contêm material transgênico, também regulamentada e de caráter 
obrigatório, ainda não se encontra implementada no país, ferindo claramente os direitos do consumidor. Portanto, tal aspecto não possibilita uma boa avaliação do estado de governança ambiental de OGMs no país.

Justiça ambiental: diversos fatores corroboram uma avaliação insatisfatória deste requisito a uma boa governança ambiental do sistema regulatório de OGMs no Brasil, tais como: a adoção da política do "fato consumado" em relação aos OGMs liberados ilegalmente em território nacional; a desresponsabilização dos produtores de OGMs ao ressarcimento dos danos econômicos provocados aos produtores de orgânicos quando da contaminação de sua produção; a ausência de monitoramento ambiental dos OGMs liberados; em alguns casos, a falta de exigência de normas de coexistência cientificamente embasadas para garantir a integridade dos sistemas de cultivo orgânicos e

\section{Referências}

BRASIL. Lei n. 9.605, de 12 de fevereiro de 1998. Dispõe sobre as sanções penais e administrativas derivadas de condutas e atividades lesivas ao meio ambiente, e dá outras providências. Brasília, DF: DOU de 12/02/1998.

. Lei n. 10.650, de 16 de abril de 2003. Dispõe sobre o acesso público aos dados e informações existentes nos órgãos e entidades integrantes do Sisnama. Brasília, DF: $D O U$ de 17/04/2003a.

. Lei $n^{\circ} 10.831$, de 23 de dezembro de 2003. Brasília, DF: DOU de 24/12/2003b.

. Lei $n^{\circ} 11.105$, de 24 de março de 2005. Regulamenta os incisos II, IV e V do $§ 1^{\circ}$ do art. 225 da Constituição Federal, estabelece normas de segurança e mecanismos de fiscalização de atividades que envolvam organismos geneticamente modificados - OGM - e seus derivados, cria o Conselho Nacional de Biossegurança - CNBS, reestrutura a Comissão Técnica Nacional de Biossegurança-CTNBio, dispõe sobre a Política Nacional de Biossegurança-PNB, revoga a Lei n. ${ }^{\circ} 8.974$, de 5 de janeiro de 1995, e a Medida Provisória n. ${ }^{\circ} 2.191-9$, de 23 de agosto de 2001, e os arts. $5 .^{\circ}, 6 .^{\circ}, 7 .^{\circ}, 8^{\circ}, 9 .^{\circ}, 10$ e 16 da Lei n. ${ }^{\circ}$ 10.814 , de 15 de dezembro de 2003 , e dá outras providências. Brasília, DF: DOU de 24/03/2005.

Decreto n. 5.705, de 16 de fevereiro de 2006. Promulga o Protocolo de Cartagena sobre Biossegurança da Convenção sobre Diversidade Biológica. Brasília, DF: DOU de 16/02/2006. convencionais; e a ausência de meios que possibilitem a participação social nos processos decisórios e as informações ambientais.

Deste modo, devido ao não atendimento dos critérios de participação social nas tomadas de decisão, acesso às informações ambientais e justiça ambiental, pode-se concluir que o sistema regulatório de OGMs no Brasil não se caracteriza por uma boa governança ambiental, requerendo medidas de correção estrutural para tanto.

\section{Agradecimentos}

Agradecemos à CAPES (Coordenação de Aperfeiçoamento de Pessoal de Nível Superior) pelo financiamento concedido.

. Ministério Público Federal. ACn. 2003.34.00.034026-

7. Parecer: Direito Constitucional, Processual Civil, Administrativo e Ambiental. Proteção do Consumidor e do Meio Ambiente. Domínio Público. Princípio da Precaução. Responsabilidade do Estado. Inconstitucionalidade. Agrotóxicos e Soja Transgênica. IDEC. Distrito Federal: Procuradoria Geral da República da 1. ${ }^{\mathrm{a}}$ Região, 2007.

COCKLIN, C.; DIBDEN, J.; GIBBS, D. Competitiveness versus "clean and Green"? The regulation and governance of GMOs in Australia and the UK. Geoforum, v. 39, p. 161-173, 2008.

COMISSÃO TÉCNICANACIONAL DE BIOSSEGURANÇA - CTNBIO. Resolução Normativa n. 19, de 19 de abril de 2000. Dispõe sobre os procedimentos para a realização de audiências públicas pela Comissão Técnica Nacional de Biossegurança. Brasília, DF: DOU de 20/04/2000.

Audiência pública do algodão geneticamente modificado. Transcrição ipsis verbis. Brasília, DF: DOU de $17 / 08 / 2007$.

CONSELHO NACIONAL DE MEIO AMBIENTE - CONAMA. Resolução CONAMA n. 001. Brasília, DF: DOU de 17/02/1986.

LEVIDOW, L. European Public Participation as Risk Governance: Enhancing Democratic Accountability for Agbiotech Policy? East Asian Science, Technology and Society: an International Journal, v. 1, p. 19-51, 2007. 
; BOSCHERT, K. Coexistence or contradiction? GM crops versus alternative agricultures in Europe. Geoforum, v. 39, n. 1, p. 174-190, 2008.

MINISTÉRIO DA AGRICULTURA, PECUÁRIA E ABASTECIMENTO. Novos tempos: a agropecuária no Brasil 20032006. Brasília: Editora Gazeta Santa Cruz, 2006.

MINARÉ, R. Onde está o Sistema de Informações em Biossegurança - SIB? Revista Cultivar. Disponível em: $<$ http:// www.portaldoagronegocio.com.br/conteudo.php?id=24733> Acesso em: agosto de 2008.

O'CONNOR, M.; HOVE, S. V. D. Prospects for public participation on nuclear risks and policy options: innovations in governance practices for sustainable development in the European Union. Journal of Hazardous Materials, v. 86, p. 77-99, 2001.

PALONIEMI, R.; TIKKA, P. M. Ecological and social aspects of biodiversity conservation on private lands. Environmental Science \& Policy, v. 2, p. 336-346, 2008.
PARANAONLINE. Justiça Federal determina suspensão de milho geneticamente modificado. 2008. Disponível em: $<$ http:// www.parana-online.com.br/editoria/cidades/news/265112/>. Acesso em: outubro de 2008.

PELAEZ, V. Biopoder e regulação da tecnologia: o caráter normativo da análise de risco dos OGMs. Ambiente e Sociedade, v. 2, n. 7, p. $145-158,2004$.

O estado de exceção no marco regulatório dos organismos geneticamente modificados no Brasil. In: CONGRESSO DA SOCIEDADE BRASILEIRA DE ECONOMIA, ADMINISTRAÇÃO E SOCIOLOGIA RURAL, 45., 2007. Anais... v. 1. Londrina, 2007.

THUSWOHL, M. Justiça volta a proibir que CTNBio libere milho transgênico. Carta Maior, 17 out. 2007. Disponível em: $<$ http://www.terrazul.m2014.net/spip.php?article497>. Acesso em: novembro de 2008.

Recebido em janeiro de 2012. Aceito em maio de 2012. Publicado em junho de 2012. 